\title{
Comportamentalismo, Cognitivismo e Humanismo: uma revisão de literatura
}

\author{
Behavioralism, Cognitivism and Humanism: A Literature Review
}

\author{
ANDRADE, Daniel Everson da Silva. Discente do curso de Mestrado em Educação \\ Profissional e Tecnológica \\ Instituto Federal de Educação Ciência e Tecnologia do Sertão Pernambucano- IF Sertão Campus Salgueiro. \\ Salgueiro - PE - Brasil. CEP: 56000-000/ Telefone: (81) 998947555 / E-mail: daniel.andrade@ifpb.edu.br
}

\author{
NETO, Antônio Ferrão Paiva Pinto. Discente do curso de Mestrado em Educação \\ Profissional e Tecnológica \\ Instituto Federal de Educação Ciência e Tecnologia do Sertão Pernambucano- IF Sertão Campus Salgueiro. \\ Salgueiro - PE - Brasil. CEP: 56000-000/ Telefone: (81) 997263919 / E-mail: aferraonet@gmail.com
}

\section{OLIVEIRA, Cristiane Ayala de. Doutora/Tecnóloga em Agroindústria}

Instituto Federal de Educação Ciência e Tecnologia do Sertão Pernambucano- IF Sertão Campus Salgueiro. Salgueiro - PE - Brasil. CEP: 56000-000/ Telefone: (87) 99664-3349 / E-mail: cristiane.ayala@ifsertao-pe.edu.br

\section{BRITO, Josilene Almeida. Doutora/Licenciatura em Ciências}

Instituto Federal de Educação Ciência e Tecnologia do Sertão Pernambucano- IF Sertão Campus Salgueiro. Salgueiro - PE - Brasil. CEP: 56000-000/ Telefone: (87) 9 96361207/ E-mail: josilene.brito@ifsertao-pe.edu.br

\section{RESUMO}

O artigo teve como objetivo realizar uma revisão narrativa de literatura com vistas a traçar um panorama histórico das teorias de aprendizagem, tendo como foco o comportamentalismo, o cognitivismo e o humanismo e suas colaborações para o campo da educação profissional tecnológica. A revisão narrativa foi escolhida como método de elaboração deste artigo por permitir uma descrição do estado da arte do tema sob o ponto de vista da fundamentação teórica, interpretação e síntese dos conceitos. Buscou-se abordar o behaviorismo de Watson (radical) e Skinner (metodológico), sendo que Skinner foi quem mais teve influência na educação, com ênfase no ensino-aprendizagem. Já no cogntivismo buscou-se abordar a ótica de Bruner, Piaget, Vergnaud, Vygotsky, Ausebel, Novak, Gowin. Por fim a concepção Humanista de Carl Rogers e Paulo Freire. Seja no campo comportamentalista, cognitivista ou humanista, conclui-se que as teorias de aprendizagem devem ser entendidas de forma crítica pelo professor.

Palavras-chave: Teorias de aprendizagem, Educação profissional tecnológica, teóricos.

\begin{abstract}
The objective of this article was to perform a narrative literature review with a view to drawing a historical overview of learning theories, focusing on behaviorism, cognitivism and humanism and their contributions to the field of technological professional education. The narrative review was chosen as the method of elaboration of this article because it allows a description of the state of the art of the subject from the point of view of the theoretical foundation, interpretation and synthesis of the concepts. We sought to address the behaviorism of Watson (radical) and Skinner (methodological), and Skinner was the one who had the most influence on education, with emphasis on teaching-learning. Already in cogntivism we sought to approach the optics of Bruner, Piaget, Vergnaud, Vygotsky, Ausebel, Novak, Gowin. Finally the humanist conception of Carl Rogers and Paulo Freire. Whether in the behavioral, cognitivist or humanist field, it is concluded that learning theories must be critically understood by the teacher.
\end{abstract}

keywords: Learning theories, Technological professional education, theorists. 

ANDRADE, D. E. da S.; NETO, A. F. P. P.; OLIVEIRA, C. A. de; BRITO, J. A. (2019).
Comportamentalismo, Cognitivismo e Humanismo: uma revisão de literatura

\section{Introdução}

A aprendizagem é um processo que caminha lado a lado com as vidas de todas as pessoas, por isso o processo de como aprender é motivo de discussão - principalmente - quando está ligado a aprendizagem formal desenvolvida nas escolas. Devemos considerar alguns aspectos no processo de ensino-aprendizagem, tais como: habilidade, atitude, interesse, personalidade e maneira de viver dos sujeitos aprendizes (ANACLETO, 2015, p. 2).

Aprender, a grosso modo, pode ser encarado como adquirir informações. Não devemos esquecer que aprender, também, envolve mudanças de comportamentos. Assim as teorias de aprendizagem têm sua origem no esforço de psicólogos ao longo da história no sentido de organizar as observações, hipóteses, palpites, leis, princípios e suposições relacionados ao comportamento humano (LEFRANÇOIS, 2017).

Em nosso artigo buscamos rever alguns pressupostos das teorias de aprendizagem com foco no behaviorismo, cognitivismo e humanismo.

\section{Material e métodos}

O artigo foi desenvolvido por meio de uma revisão narrativa como procedimento metodológico. Buscamos conceitos para desenvolver um apanhado histórico das teorias de aprendizagem, com foco no behaviorismo, cognitivismo e humanismo. É através da revisão da literatura que os trabalhos acadêmicos são situados dentro das grandes áreas de pesquisa em que estão dispostos (PRODANOV E FREITAS, 2013, p. 78).

A revisão de literatura consiste na descrição do que já se conhece sobre o problema que se quer investigar, ou seja, o "estado da arte" em determinada área do conhecimento. Pode ser definida como uma síntese comentada da bibliografia teórica ou temática, relacionada ao projeto que se quer desenvolver (PÁDUA, 2018, p. 176).

A revisão narrativa foi escolhida como método de elaboração deste artigo por permitir uma descrição do estado da arte do tema sob o ponto de vista da fundamentação teórica, interpretação e síntese dos conceitos. Embora o método de revisão narrativa não utilize critérios explícitos e sistemáticos no processo de busca e análise crítica da literatura durante o levantamento bibliográfico, permite basicamente, uma análise preliminar da literatura e sua interpretação após análise secundária (BERNARDO; NOBRE; JANETE, 2004).

Pela limitação do método escolhido, não foram aplicadas estratégias exaustivas de busca sofisticada, contudo os autores de base consultados (Bock, La Rosa Lenfrançois, Moreira e Sternberg) para a exposição das teorias aqui apresentadas são referências importantes para discorrermos sobre os estudos das teorias de aprendizagem que abordam o comportamentalismo, o cognitivismo e o humanismo.

Embora limitada do ponto de vista metodológico, o levantamento bibliográfico da nossa 
ANDRADE, D. E. da S.; NETO, A. F. P. P.; OLIVEIRA, C. A. de; BRITO, J. A.(2019). Comportamentalismo, Cognitivismo e Humanismo: uma revisão de literatura

pesquisa recorreu a materiais publicados em livros, jornais, revistas, periódicos, anais de eventos, dissertações e teses.

\section{Resultados e discussão}

O termo behaviorismo foi utilizado pela primeira vez em 1913 por John B. Watson, nos Estados Unidos. Foi quando Watson publicou um artigo intitulado de Psicologia: como behavioristas a vêem. O termo na língua inglesa significa "comportamento", graças a essa denominação é que a tendência também ficou bastante conhecida como comportamentalismo (BOCK, FURTADO, TEIXEIRA, 2001, p. 57; FREIRE, 2002, p. 67; MOURA, 2016, p. 7; LEFRANÇOIS, 2017, p. 47; MOREIRA, 2018, p. $96)$.

0 termo behaviorismo acabou por significar uma preocupação com os aspectos observáveis do comportamento. Segunda essa linha teórica, o comportamento consiste de respostas que podem ser observadas e relacionadas a outros eventos observáveis, como as condições que 0 precedem e se seguem a ele (LEFRANÇOIS, 2017, p. 45).

Watson teria se baseado nos estudos de psicologia animal que já estavam bem encaminhados no florescer do século XX, graças aos estudos de Ivan Pavlov (1849-1936), que procurava explicar que toda aprendizagem estava ligado ao condicionamento (FREIRE, 2002; MOREIRA, 1999).

Ivan Pavlov influenciou o behaviorismo graças aos seus experimentos realizados com cães. Pavlov percebeu, através de observações, que a simples presença do tratador de cães com o prato de comida fazia com que os mesmos salivassem (LEFRANÇOIS, 2017, p. 36).

Foi no estudo com animais em laboratório, em especial a digestão de cães, que Pavlov percebeu que alguns estímulos provocavam a salivação e a secreção estomacal no animal, o que deveria ocorrer apenas quando o animal ingerisse um alimento. A partir disso, ele percebeu que o comportamento do cão estava condicionado a esses estímulos, normalmente aplicados poucos instantes antes do cão se alimentar. (OSTERMANN E CAVALCANTI, 2011, p. 14).

Esse estudo recebeu o nome de reflexo condicionado e foi utilizada pelos behavioristas para o estudo dos processos psíquicos. Foi através da técnica do condicionamento que tornou-se possível estudar os processos de elaboração do comportamento (FREIRE, 2002. p. 68). "A teoria do condicionamento Respondente de Pavlov se enquadra na ampla categoria de teorias que podem ser descritas em termos de estimulo e reposta" (LA ROSA, 2003, p. 41).

No experimento com os cães a comida refere-se ao estímulo incondicionado (US), por tratar-se de um evento ambiental que afetava organismo dos cães. Já a salivação, advinda da resposta a presença do alimento, foi chamada de resposta condicionada (UR), por estar atrelada a um (US). Pavlov provou que se um US fosse ligado a outro estímulo, repetidas vezes, poderia desencadear outro estímulo provocado originalmente pelo US, que nesse caso seria a salivação, nomeado de estímulo condicionado, dessa maneira toda vez que soasse uma campainha os cães 
ANDRADE, D. E. da S.; NETO, A. F. P. P.; OLIVEIRA, C. A. de; BRITO, J. A.(2019). Comportamentalismo, Cognitivismo e Humanismo: uma revisão de literatura

salvariam (LEFRANÇOIS, 2017, p. 36).

Resumidamente o behaviorismo pode ser classificado em dois tipos: metodológico e radical. A primeira vertente foi criada por Burrhus Frederic Skinner (1904-1990), que ficou mais conhecido apenas como Skinner. De acordo com os radicais o homem não passava de uma tábua rasa sem nenhum atributo fisiológico e genético. Por sua vez o behaviorismo metodológico tem um caráter empirista, para Watson (seu fundador) o ser humano aprendia tudo com o ambiente, o homem estaria subjugado ao meio. De acordo com essa vertente o homem não possui nenhuma herança biológica, o homem nascia vazio, ou seja: era uma tábua rasa ipsis litteri como os radicais pregavam (OSTERMANN E CAVALCANTI, 2011, p. 14; RESENDE, 2018, p. 95).

Figura 1 - Exemplo de um estímulo condicionado

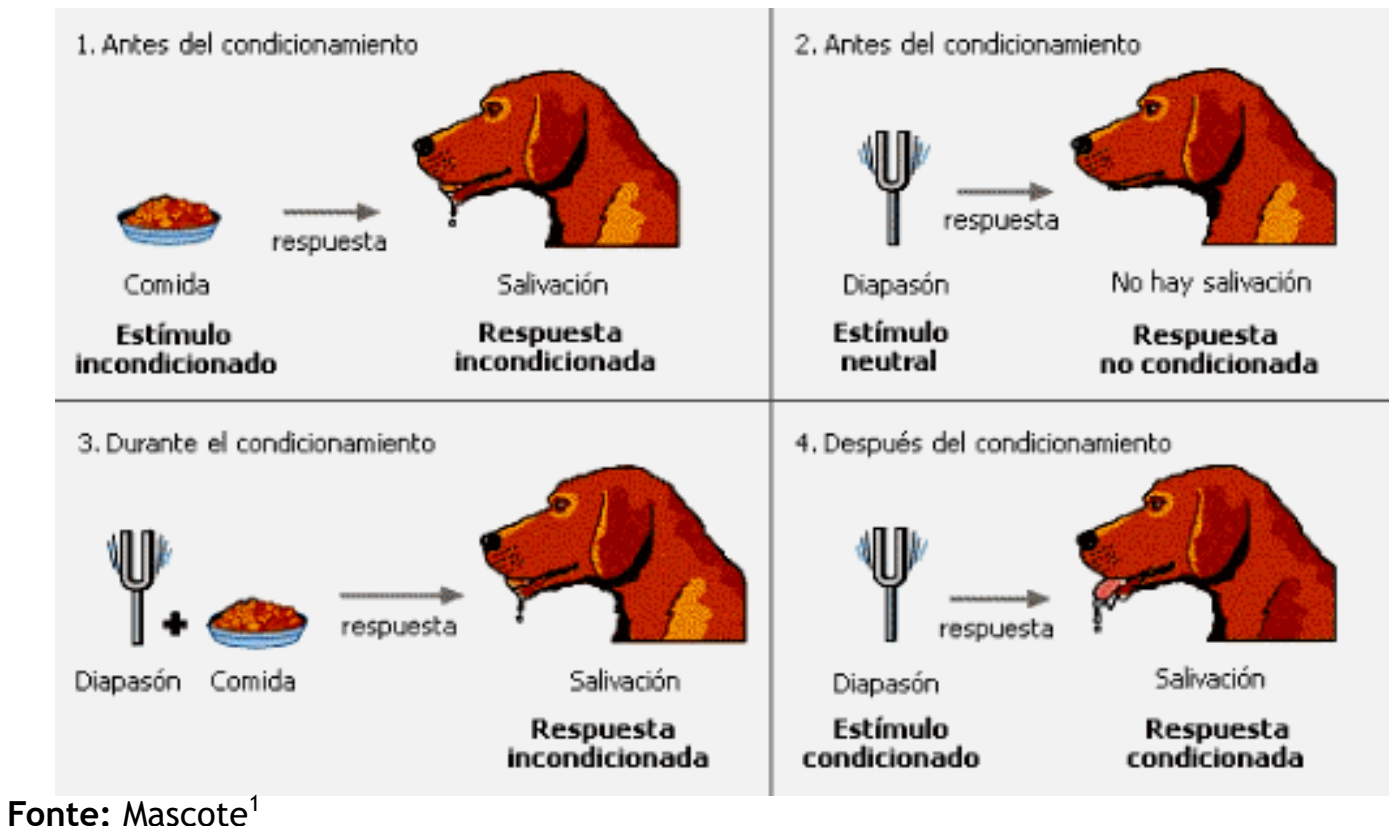

O behaviorismo, apesar de Skinner e Watson terem tido bastante destaque, teve muitos outros nomes ilustres, tais como: Floyd Allport; Albert Weiss; Edwin B. Holt; Waiter S. Hunter; Karl S. Lashley; Clark L. Hull; Edward C. Tolman; Guthrie; Max Meyer; Lorenz; Skinner e Gagné (FREIRE, 2002, p. 69). No entanto nos deteremos em nossa revisão de literatura a tratar da abordagem de Skinner com foco nas teorias de aprendizagem.

\section{O behaviorismo na educação}

Skinner foi quem mais teve influência na educação, com ênfase no ensino-aprendizagem e na prática escolar, apesar dele não se considerar um teórico da aprendizagem. (MOREIRA, 1999; FREIRE; 2002; OSTERMANN E CAVALCANTI, 2011).

1 https://www.mascotarios.org/pt/el-comportamiento-sociocognitivo-de-los-perros-se-asemeja-al-de-un-ninopequeno/ 
ANDRADE, D. E. da S.; NETO, A. F. P. P.; OLIVEIRA, C. A. de; BRITO, J. A.(2019). Comportamentalismo, Cognitivismo e Humanismo: uma revisão de literatura

Skinner foi o teórico behaviorista que mais influenciou o entendimento do processo ensino- aprendizagem e a prática escolar. No Brasil, a influência da pedagogia tecnicista remonta à segunda metade dos anos 50 , mas foi introduzida mais efetivamente no final dos anos $60 \mathrm{com}$ o objetivo de inserir a escola nos modelos de racionalização do sistema de produção capitalista OSTERMANN E CAVALCANTI, 2011, p. 21)

O ponto de vista da aprendizagem sob a ótica de Skinner tem relação com a questão da modificação do desempenho, para ele o bom ensino carece de organizar com eficiência as condições estimuladoras. 0 aluno deverá sair de uma situação de aprendizagem diferente de como entrou. 0 ensino é visto como um processo condicionador gerido através do uso de reforço de respostas que se deseja obter (OSTERMANN E CAVALCANTI, 2011, p. 13).

Skinner sugeriu mudanças no processo de ensino-aprendizagem, na visão dele o professor sozinho não seria capaz de dar o reforço necessário, simultaneamente, a todos os alunos em um ambiente escolar. Para tanto Skinner acreditava que a introdução de instrumentos mecânicos seriam capazes de cumprir esta missão auxiliando o docente. Dessa forma vieram à tona as máquinas de ensinar, que funcionavam da seguinte maneira: toda vez que o aluno respondesse corretamente a uma questão proposta pela máquina, através de mecanismos, ela avançaria de nível questionando o aluno com uma nova pergunta - tal fato poderia está relacionado com um som, funcionando como um tipo de reforço. Caso a resposta não estivesse correta o som não seria emitido e o estudante faria uma nova tentativa. Há relatos de que essas máquinas lograram resultados exitosos onde foram implantadas, contudo apresentaram maior efetividade na indústria (RESENDE, 2018, P. 95-96).

Na perspectiva skinneriana, o ensino se dá apenas quando o que precisa ser ensinado pode ser colocado sob controle de certas contingências de reforço. O papel do professor no processo instrucional é o de arranjar as contingências de reforço, de modo a possibilitar ou aumentar a probabilidade de que o aprendiz exiba o comportamento terminal, isto é, que ele dê a resposta desejada (a ser aprendida) (MOREIRA, 1999, p. 59).

De acordo com Ostermann e Cavalcanti (2011, p. 22) o processo de ensino proposto por Skinner divide-se nas seguintes etapas:

a) Estabelecimento de comportamentos terminais, através de objetivos instrucionais;

b) Análise da tarefa de aprendizagem, a fim de ordenar sequencialmente os passos da instrução;

c) Executar o programa, reforçando gradualmente as respostas corretas correspondentes aos objetivos.

Por fim o enfoque skinneriano é bastante criticado por promover uma aprendizagem mecânica/automática. Mas o próprio Skinner (2003 apud KALFUSS, 2015, p. 9) deixa claro que os controles já existiam antes dele. 
ANDRADE, D. E. da S.; NETO, A. F. P. P.; OLIVEIRA, C. A. de; BRITO, J. A.(2019). Comportamentalismo, Cognitivismo e Humanismo: uma revisão de literatura

\section{O Cognitivismo}

A psicologia cognitiva, em detrimento do behaviorismo, está interessada nos processos mentais superiores em contraposição ao comportamento observável. Tem como foco de estudo como as pessoas percebem, aprendem, lembram e pensam a informação. Além de ter cambiado o foco da pesquisa com animais para a prioritariamente a pesquisa com humanos (STERNBERG, 2008, p. 40; LEFRANÇOIS, 2015, p. 2016). Lefrançois (2015) desenvolveu uma com as principais diferenças entre o behaviorismo e o cognitivismo:

Tabela 1 - Diferenças básicas entre o behaviorismo e o cognitivismo:

\begin{tabular}{|l|l|l|}
\hline & Behaviorismo & Cognitivismo \\
\hline Conceitos principais & $\begin{array}{l}\text { Estímulos, respostas, } \\
\text { contiguidade, reforçamento }\end{array}$ & $\begin{array}{l}\text { Processos mentais superiores } \\
\text { (pensamento, imaginação e } \\
\text { solução de problemas) }\end{array}$ \\
\hline Metáforas principais & $\begin{array}{l}\text { Qualidades mecânicas do do } \\
\text { funcionamento humano }\end{array}$ & $\begin{array}{l}\text { Metáfora de processamento da } \\
\text { informação e as baseadas em } \\
\text { computador }\end{array}$ \\
\hline $\begin{array}{l}\text { Sujeitos de pesquisa mais } \\
\text { comum }\end{array}$ & $\begin{array}{l}\text { Animais; algumas pesquisas } \\
\text { com sujeitos humanos }\end{array}$ & $\begin{array}{l}\text { Humanos; pesquisas com } \\
\text { alguns animais não humanos }\end{array}$ \\
\hline Objetivos principais & $\begin{array}{l}\text { Descobrir relações previsíveis } \\
\text { entre estimulos, respostas e } \\
\text { consequências das respostas }\end{array}$ & $\begin{array}{l}\text { Fazer interferências úteis } \\
\text { sobre os processos mentais } \\
\text { que influenciam e determinam } \\
\text { o comportamento }\end{array}$ \\
\hline Amplitude das teorias & $\begin{array}{l}\text { Geralmente pretendem } \\
\text { explicar todos os aspectos } \\
\text { significativos } \\
\text { comportamento do }\end{array}$ & $\begin{array}{l}\text { Geralmente mais limitadas em } \\
\text { amplitude; buscam explicar } \\
\text { processos e comportamentos } \\
\text { mais específicos }\end{array}$ \\
\hline
\end{tabular}

Fonte: Lefrançois (2015, p. 2017).

Embora Bruner, Piaget e Vygotsky sejam autores cognitivistas muito referenciados na literatura com contribuições relevantes no campo educacional, não podemos desconsiderar em nossa breve revisão os estudos de Ausubel, Novak e Gowin. Todavia, é importante ressaltar que Novak e Gowin, segundo a abordagem de Moreira (2019), apresentam em suas teorias elementos estruturadores oriundos dos campos cognitivista e humanista, motivo pelo qual seus estudos situamse na fronteira entre essas duas escolas.

\section{Teoria da aprendizagem de Bruner}

Jerome Seymour Bruner ou simplesmente Jerome Bruner nasceu em 1915 e faleceu recentemente em 2016. Apesar de ter escrito vários livros na área de psicologia, área em que foi bastante atuante tendo sido influenciado pela revolução cognitiva dos anos 50, também ficou bastante conhecido devido a sua atuação na área de educação (RABATINI, 2010, p. 24; MOREIRA, 2013, p. 24). 
ANDRADE, D. E. da S.; NETO, A. F. P. P.; OLIVEIRA, C. A. de; BRITO, J. A. (2019). Comportamentalismo, Cognitivismo e Humanismo: uma revisão de literatura

Para Bruner, de acordo Moreira (1999, p. 81) e Ostermann Cavalcanti (2011, p. 31), “é possível ensinar qualquer assunto, de uma maneira honesta, a qualquer criança em qualquer estágio de desenvolvimento". De acordo com Bruner o aluno deveria ter uma grande participação no processo de aprendizagem, ele apresenta uma teoria de aprendizagem estabelecida por regras visando dispor a melhor maneira de poder se obter o conhecimento (PRÄSS, 2012, p. 23; SILVA, 2017, p. 16).

Bruner foi um dos nomes mais importantes, quando falamos em construtivismo, de acordo com Niemann e Brandoli (2012, p. 2) essa teoria veio à tona durante o século XX e teve como seu precursor Jean Piaget, o mesmo através da observação de crianças, desde a concepção até a adolescência, concluiu que o conhecimento é construído na interação do sujeito e do meio em que ele vive (nos aprofundaremos mais no tema na seção do artigo que trata especificamente de Piaget).

No Livro 0 processo da educação Bruner ressalta que o aprendizado, e o ato de aprender, está ligado a três processos quase simultâneos: Aquisição de nova informação, transformação e avaliação Crítica (BRUNE, 1976, p. 44-45 apud FILIPPI; BORTOLINI; DIAS, 2012, p. 3-4).

Bruner dá ênfase à aprendizagem pela descoberta, que de acordo Lefrançois (2017, p. 231): "parte da premissa de que a formação de sistemas codificações genéricos requer a descoberta de relações. [...] Defende o uso de técnicas pelas quais as crianças são encorajadas a descobrir fatos e relações por si próprias." Para Bruner a aprendizagem é um processo ativo e não processo passivo.

Ainda, de acordo com Lefrançois (2017, p. 231), para Bruner um currículo em espiral é mais indicada quando se visa uma educação centrada no aprendiz. Na prática o currículo em espiral seria a repetição de tópicos de ensino em idades ou em níveis de graduação, de forma que o assunto fosse dado gradualmente aumentando de nível de acordo com o decorrer da vida estudantil do sujeito em suma:

O conceito de aprendizagem em espiral pode enunciar-se da seguinte forma: qualquer ciência pode ser ensinada, pelo menos nas suas formas mais simples, a alunos de todas as idades, uma vez que os mesmos tópicos serão, posteriormente, retomados e aprofundados mais tarde (FILIPPI; BORTOLINI; DIAS, 2012, p. 4).

Figura 2 - Esquema do currículo em espiral

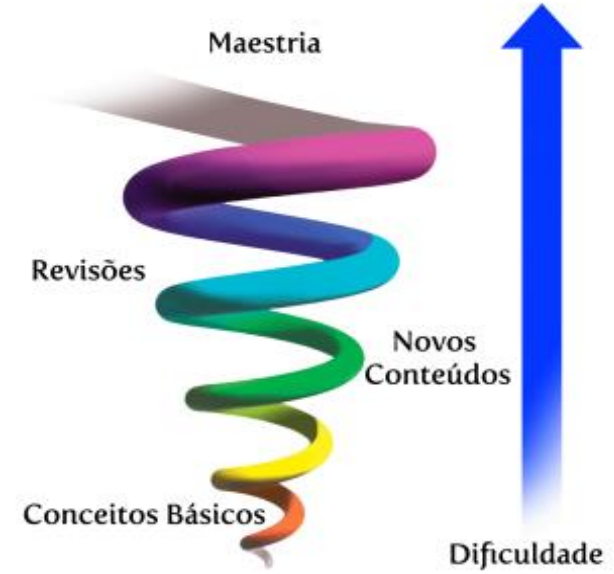

Fonte: http://www.oexplorador.com.br/117232/ 
ANDRADE, D. E. da S.; NETO, A. F. P. P.; OLIVEIRA, C. A. de; BRITO, J. A.(2019). Comportamentalismo, Cognitivismo e Humanismo: uma revisão de literatura

Enfim os textos mais recentes de Bruner trataram de como nós entendemos a realidade, e de como nós fazemos uso de narrativas pessoais para que possamos dar sentido às nossas vidas. Bruner foi um dos grandes defensores da metodologia de ensino construtivista, apesar de não concordar totalmente com Piaget (LEFRANÇOIS, 2017, p. 261).

\section{A teoria do desenvolvimento cognitivo de Piaget e suas contribuições no campo educacional}

Diferentemente das ideias defendidas pelo comportamentalismo, que tem como base o comportamento psicomotor humano observável, Piaget, considerado o precursor da linha construtivista nos processos de ensino-aprendizagem, fundamenta sua teoria na ação mental humana - desenvolvimento cognitivo, considerando o pensamento como a interiorização da ação. As contribuições de Piaget para a educação se deram em virtude dos seus estudos da psicologia para fundamentar e explicar o crescimento cognitivo da criança, o qual, segundo a abordagem piagetiana, se dá por meio da construção de esquemas de assimilação mental para que a realidade seja compreendida.

Piaget classifica esses esquemas mentais em duas categorias, aos quais chamou de assimilação e acomodação. Como toda abordagem à realidade pressupõe um esquema de assimilação, no momento em que a mente assimila ela incorpora a realidade a seus esquemas de ação. Quando esses esquemas de ação não assimilam uma situação a mente desiste ou se modifica. Caso a mente se modifique, ocorre o fenômeno da acomodação, que leva a construção de novos esquemas de assimilação (reestruturação da assimilação). É nesse momento que ocorre o desenvolvimento da arquitetura cognitiva do sujeito. Portanto, segundo a abordagem piagetiana, a aprendizagem só acontece quando o esquema mental de assimilação sofre acomodação, ou seja, quando a mente do indivíduo se modifica.

Para Ostermann e Cavalcanti (2011), Piaget considera a mente uma estrutura que precisa funcionar em equilíbrio para promover o desenvolvimento mental,

No entanto, quando esse equilíbrio é rompido por experiências não assimiláveis, a mente sofre acomodação a fim de construir novos esquemas de assimilação e atingir novo equilíbrio. Esse processo de reequilíbrio é chamado de equilíbrio majorante e é o responsável pelo desenvolvimento mental do indivíduo. Portanto, na abordagem piagetiana, ensinar significa provocar o desequilíbrio na mente da criança para que ela, procurando o reequilíbrio, se reestruture cognitivamente e aprenda (OSTERMANN; CAVALCANTI, 2011, p. 33).

Para Moreira (2016), o equilíbrio, chamado por Piaget de equilibração, "é, por excelência, o mecanismo piagetiano para descrever a melhora ou o aumento de conhecimento ou, em última análise, o próprio desenvolvimento cognitivo do sujeito". O ensino deve conduz à equilibração majorante para que haja a aprendizagem, embora a desequilibração cognitiva seja necessária, não pode ser tão grande a ponto de não conduzir à equilibração majorante.

Portanto, os processos envolvidos no desenvolvimento cognitivo, segundo a teoria piagetiana, 
ANDRADE, D. E. da S.; NETO, A. F. P. P.; OLIVEIRA, C. A. de; BRITO, J. A. (2019) Comportamentalismo, Cognitivismo e Humanismo: uma revisão de literatura

podem ser divididos em cinco conceitos-chave: Adaptação, organização, assimilação, acomodação e equilibração majorante. Embora os processos sejam sempre os mesmos, Piaget ressalta que eles ocorrem de maneira diferente na mente de um adulto, adolescente ou criança.

Os estudos de Piaget trazem muitas contribuições e carecem de um maior aprofundamento para serem compreendidos em sua plenitude. Além da breve exposição aqui apresentada, a abordagem piagetiana apresenta estudos muito interessantes que envolvem a teoria da contribuição, a ideia de ação, o estudo da causalidade e os métodos ativos. Inclusive as pesquisas de Osterman e Cavanci (2011) falam sobre o uso de métodos ativos para o ensino de ciências, principalmente no campo da física.

\section{A teoria sócio-histórica de Vygotsky}

Os estudos de Vygotsky emergiram no período após a Revolução Russa de 1917. Na perspectiva vygotskyana, o desenvolvimento cognitivo necessita da relação do indivíduo com o contexto social, histórico e cultural no qual está inserido. A premissa do desenvolvimento cognitivo, para Vygotsky, é a conversão dessas relações sociais estabelecidas em funções mentais superiores. Portanto, as construções sócio-históricas e culturais, geradas na interação do ser com o meio social, são imprescindíveis para que a pessoa se desenvolva cognitivamente por meio de um processo de reestruturação mental que promove ganhos na aprendizagem.

Segundo Neves e Damiani (2016):

O ponto de vista de Vygotsky é que o desenvolvimento humano é compreendido não como a decorrência de fatores isolados que amadurecem, nem tampouco de fatores ambientais que agem sobre o organismo controlando seu comportamento, mas sim como produto de trocas recíprocas, que se estabelecem durante toda a vida, entre indivíduo e meio, cada aspecto influindo sobre o outro (NEVES; DAMIANI, 2006, p. 7).

$\mathrm{Na}$ teoria vygotskyana, a conversão das relações sociais em funções mentais superiores ocorre por meio da mediação, que inclui o uso de instrumentos e signos. Para Moreira (2019):

Um instrumento é algo que pode ser usado para fazer alguma coisa; um signo é algo que significa alguma coisa. [...] as palavras são signos linguísticos. A linguagem é um sistema articulado de signos. As sociedades constroem instrumentos e sistemas de signos; ambos são construídos ao longo da história dessas sociedades e modificam, influenciam, seu desenvolvimento social e cultural. É através da apropriação (internalização) dessas construções sócio-históricas e culturais, via "interação social", que o indivíduo se desenvolve cognitivamente.

Para Vygotsky, é por meio de acesso a esses signos e sistemas de signos que a estrutura cognitiva se constrói e o desenvolvimento individual do sujeito acontece. Portanto, a gama de atividades que um estudante tem potencialidade para aprender se amplia à medida que ele internaliza (se apropria) mais instrumentos e signos por meio as relações sociais que estabelece. Nesse processo de construção cognitiva, o desenvolvimento, conforme a Lei de Dupla Formação de Vygotksy, ocorre primeiro em nível social (interpessoal) e depois em nível individual (intrapessoal). 
ANDRADE, D. E. da S.; NETO, A. F. P. P.; OLIVEIRA, C. A. de; BRITO, J. A.(2019) Comportamentalismo, Cognitivismo e Humanismo: uma revisão de literatura

Enquanto Piaget defendia a necessidade de aguardar a formação de algumas estruturas mentais para que a aprendizagem de um determinado conceito se concretizasse, Vygotsky afirma que o ensino e a interação social é que vão desencadear as estruturas mentais necessárias à aprendizagem, contudo ressalta que não é preciso ultrapassar a capacidade cognitiva do aprendiz quando se busca criar novas estruturas mentais. É preciso respeitar o que chamou de Zona de Desenvolvimento Proximal (VYGOTSKY, 1991).

Para Vygotsky (1991), a Zona de Desenvolvimento Proximal representa a distância entre o nível de desenvolvimento real que a pessoal possui e o seu nível de desenvolvimento potencial. Essa distância é uma medida do potencial de aprendizagem do sujeito, representando as funções que ainda estão em processo de maturação, ou seja, que ainda não se desenvolveram plenamente. Embora a interação social seja algo muito valorizado na teoria vygotskyana, essa interação só provocará a aprendizagem no sujeito se ela ocorrer dentro do Zona de Desenvolvimento Proximal.

Enquanto outras correntes teóricas defendem que o desenvolvimento cognitivo é necessário para que aprendizagem ocorra, na perspectiva vygotskyana a aprendizagem precede o desenvolvimento. Vygotsky considera que a aprendizagem só é boa quando ela avança em relação ao desenvolvimento, portanto quando a aprendizagem não ultrapassa os níveis de desenvolvimento já alcançados por um aluno ela não contribui para o seu desenvolvimento cognitivo.

Para Moreira (1990), o papel do professor, na perspectiva vygotskyana, é o de mediador, pois ele já internalizou significados compartilhados (socialmente, culturalmente e historicamente) dentro da sua área de atuação que precisam ser ensinados para os seus alunos. 0 professor deve ser um mediador neste processo, no qual ele apresenta determinados signos aos alunos de maneira contextualizada a uma área de ensino a fim de prover um intercâmbio de significados. Portanto, a aprendizagem se concretiza (ocorre o desenvolvimento cognitivo) quando professor e aluno conseguem partilhar esses significados por meio de uma interação social (ex: uma aula) dentro da zona de desenvolvimento proximal.

\section{Vergnaud e a teoria dos campos conceituais na construção cognitiva da aprendizagem}

Considerado um discípulo de Piaget, Gerard Vergnaud ampliou os estudos deste ao descrever o funcionamento cognitivo da mente humana a partir da formulação da teoria dos campos conceituais, sua contribuição teórica mais relevante no campo das teorias da aprendizagem. Com um viés psicológico cognitivista, Vergnaud tentou provar, por meio do que chamou de campos conceituais, a estrutura geral que organiza o conhecimento. A teoria dos campos conceituais de Vergnaud bebe fundo no conceito de esquema, de Piaget. Esse conceito explica a forma de organização (modelo mental) das habilidades intelectuais, sensoriais e motoras das crianças.

Embora Vergnaud considere o conceito de esquema no processo de aprendizagem, tal qual Piaget, ele amplia essa percepção ao levar em consideração as características das situações em que os esquemas se aplicam para mostrar que é por meio das situações que os conceitos ganham sentido, tornando-se, assim, significativos para a aprendizagem. 
ANDRADE, D. E. da S.; NETO, A. F. P. P.; OLIVEIRA, C. A. de; BRITO, J. A. (2019) Comportamentalismo, Cognitivismo e Humanismo: uma revisão de literatura

Para Moreira (2019), seja dentro ou fora da escola, o aluno desenvolve sua aprendizagem segundo a concepção cognitivista - a partir dos aspectos conceituais dos esquemas e da análise conceitual de situações. As matérias estudadas em sala de aula pelos estudantes, por exemplo, assim como outros ramos do conhecimento de uma forma geral, possuem campos conceituais para os quais esquemas cognitivos (modelos mentais de organização dos conhecimentos) se desenvolvem para a materialização mental de concepções específicas para o entendimento desses assuntos.

Analisando criticamente a teoria dos campos conceituais de Vergnaud com os estudos de Piaget, Moreira (2019 p. 207) afirma:

[...] é uma teoria cognitivista neopiagetiana que pretende oferecer um referencial mais frutífero do que 0 piagetiano ao estudo do desenvolvimento cognitivo e da aprendizagem de competências complexas, particularmente aquelas implicadas nas ciências e na técnica, levando em conta os próprios conteúdos do conhecimento e a análise conceitual de seu domínio.

Além de Piaget, Vygotsky também foi outro teórico que serviu de inspiração para Vergnaud na formulação da sua teoria dos campos conceituais. A influência vygotskyana sobre Vergnaud reside na importância das interações sociais e no papel do professor como mediador do aluno no processo de desenvolvimento da aprendizagem. Como Vergnaud considera o domínio do campo conceitual essencial para a construção da aprendizagem, o professor deve oportunizar condições favoráveis (situações) para que essa construção aconteça de maneira significativa.

\section{A teoria da aprendizagem significativa de Ausubel}

A teoria da aprendizagem significativa de Ausubel recorre à abordagem cognitivista para formular as suas concepções com foco nos aspectos ligados predominantemente à aprendizagem. Embora Ausubel não desconsidere a afetividade no processo de aprendizagem, sua teoria é fortemente voltada para a importância da estrutura cognitiva (corpo de conhecimentos - seu conteúdo e organização) do indivíduo para o desenvolvimento da aprendizagem.

Para Moreira (2016, p. 31):

A aprendizagem significativa é aquela em o significado do novo conhecimento vem da interação com algum conhecimento especificamente relevante existente na estrutura cognitiva do aprendiz com um certo grau de estabilidade e diferenciação. Nesta interação, não só o novo conhecimento adquire significado, mas também o conhecimento anterior fica mais rico, mais elaborado, adquire novos significados.

Ausubel considera que os conhecimentos que são do domínio de uma pessoa - aquilo que o estudante já sabe - é o fator que mais influência a aprendizagem, tendo em vista que esses conhecimentos, já consolidados na estrutura cognitiva do estudante, poderão sofrer modificações por meio da alteração dessas estruturas sob a influência dos novos conhecimentos adquiridos. A aprendizagem significativa tem como ponto-chave a interação entre os conhecimentos existentes e os conhecimentos novos.

O conceito de aprendizagem significativa de Ausubel está pautado na relação cognitiva que 
ANDRADE, D. E. da S.; NETO, A. F. P. P.; OLIVEIRA, C. A. de; BRITO, J. A. (2019) Comportamentalismo, Cognitivismo e Humanismo: uma revisão de literatura

o indivíduo estabelece quando assimila uma informação nova à estrutura de conhecimentos preexistentes, de modo que o cérebro humano, na perspectiva ausubeliana, guarda informações e registra as experiências sensoriais de maneira organizada e não-arbitrária. A essa estrutura de conhecimentos já existente na estrutura cognitiva do indivíduo Ausubel chamou de subsunçores, os quais podem representar algum conhecimento específico, conceito claramente definido ou ideia estabelecida já consolidados mentalmente. Em oposição à aprendizagem significativa, Ausubel considera que quando a tentativa de assimilação de novos conhecimentos acontece com pouca ou nenhuma interação com a estrutura cognitiva existente - nem tampouco a modifica - ela é chamada de aprendizagem mecânica ou automática (arbitrária), não tendo, portanto, a mesma relevância que a aprendizagem significativa.

Outra contribuição importante nos estudos de Ausubel refere-se aos conceitos de aprendizagem por recepção, na qual a forma final da informação é apresentada direta e explicitamente ao estudante; e a aprendizagem por descoberta, em que o estudante percorre um caminho independente na busca da informação principal. Contudo, é importante destacar que ambas as formas de aprendizagem (por recepção ou por descoberta), na concepção ausubeliana, só serão consideradas significativas se promoverem uma incorporação cognitiva não-arbitrária, ou seja, por meio do acionamento de subsunçores adequados que, ancorados a novos conhecimentos, promoverá uma assimilação de novos significados resultando em uma nova estrutura cognitiva mais organizada.

No que se refere ao trabalho docente, segundo a concepção ausubeliana, o papel do professor como mediador é fundamental para o desenvolvimento de aprendizagem. Neste enfoque, é necessário que o professor dê importância aos conhecimentos prévios trazidos pelos alunos, de modo que a sua intervenção didática provoque a ancoragem entre esses conhecimentos e os novos conhecimentos, para que, de fato, a aprendizagem significativa seja construída por meio dessa interação.

\section{Novak e Gowin: teorias de transição entre o cognitivismo e o humanismo}

As contribuições para a educação de Joseph D. Novak e D. Bob Gowin possuem referenciais com origem nos campos cognitivista e humanista. Novak, por exemplo, bebe diretamente na fonte da teoria da aprendizagem significativa, de Ausubel, para formular a sua teoria da educação. Tomando como ponto de partida os conceitos de aprendizagem significativa de Ausubel, fortemente ancorados no cognitivismo, Novak amplia os horizontes do seu estudo ao evidenciar a importância dos sentimentos na relação professor-aluno no processo de aprendizagem. Novak elenca cinco elementos estruturadores como base da sua teoria educacional, são eles: aprendiz, professor, conhecimento, contexto e avaliação. Para Moreira (2019), a premissa básica da teoria de Novak leva em consideração o que os seres humanos pensam, sentem e fazem, de modo que "qualquer evento educativo implica uma ação para trocar significados e sentimentos entre professores e alunos" ( $p$. 177).

Novak é um colaborador e divulgador dos estudos de Ausubel, sobretudo pelo fato de destacar a aprendizagem significativa (campo construtivista/cognitivista) como um conceito-chave 
ANDRADE, D. E. da S.; NETO, A. F. P. P.; OLIVEIRA, C. A. de; BRITO, J. A.(2019) Comportamentalismo, Cognitivismo e Humanismo: uma revisão de literatura

em sua teoria, mas a experiência afetiva (campo humanista) no ato educativo tem uma relevância muito grande. É por isso que essa fusão de elementos que embasam os estudos de Novak revela explicitamente, segundo a abordagem de Moreira, a qual escolhemos para a nossa análise, uma teoria de transição entre a escola cognitivista e a escola humanista. 0 conceito de evento educativo, tão propalado na teoria de Novak, é uma ação concreta fundamental para o desenvolvimento da aprendizagem, contudo é preciso que haja, efetivamente, uma troca de significados e uma troca de sentimentos (experiência afetiva). Como proposta de estratégia educativa, o uso de mapas conceituais pode contribuir para o alcance da aprendizagem significativa.

Assim como Novak, Gowin também encontra-se na transição entre a corrente cognitivista e humanista. Seu modelo de ensino-aprendizagem, como teoria da educação, segundo Moreira (2019), estabelece uma relação entre professor, materiais educativos e alunos. 0 compartilhamento de significados entre professor e aluno dentro de uma área de conhecimento, suportado por materiais educativos, é condição determinante nos estudos de Gowin para que o ensino efetivamente seja consumado. Entre outras contribuições para a educação, o processo de produção do conhecimento é apresentado de maneira estruturada nos estudos de Gowin por meio de um instrumento heurístico chamado de Vê epistemológico.

\section{Humanismo}

A concepção humanista de aprendizagem é uma abordagem filosófica que coloca o ser humano como figura central no processo de ensino-aprendizagem. Enquanto no comportamentalismo (behaviorismo) a ênfase se concentra no comportamento psicomotor observável e mensurável no mundo exterior, bem como em suas consequências por meio de respostas aos estímulos, e no cognitivismo (construtivismo) a centralidade parte das estruturas cognitivas que armazenam informações de maneira organizada na mente das pessoas para construírem as estruturas de aprendizagem estabelecendo relações de significado, a "teoria de aprendizagem" com viés humanista valoriza o todo que forma o ser humano numa estrutura holística, a qual compreende um conjunto integrado e indissociável de ações, pensamentos e sentimentos, valorizando, fundamentalmente, os aspectos afetivos e emocionais no desenvolvimento da aprendizagem do aluno. A perspectiva de ensino com viés humanista deve contribuir efetivamente para o crescimento e a auto realização do indivíduo no processo de ensinoaprendizagem.

Para Leão (2014), a troca de experiências entre o sujeito e o objeto, por meio de conflitos e interações, é imprescindível para que a aprendizagem se solidifique. A relação afetiva e social que se constrói ao longo deste processo pode proporcionar ganhos reais para a aprendizagem os quais não eram levados em consideração nas abordagens de aprendizagem comportamentalista e cognitivista.

Segundo Moreira (1999), a aprendizagem adquirida por meio da afetividade deve levar em consideração experiências que envolvem "prazer e dor, satisfação ou descontentamento, alegria ou ansiedade". Em defesa de um planejamento curricular docente que valorize os aspectos comportamentais da aprendizagem, o autor destaca a importância das relações interpessoais serem 
ANDRADE, D. E. da S.; NETO, A. F. P. P.; OLIVEIRA, C. A. de; BRITO, J. A.(2019) Comportamentalismo, Cognitivismo e Humanismo: uma revisão de literatura

efetivamente levadas em consideração para que o desejo de aprender seja despertado no aluno, assim como as necessidades reais de aprendizagem dos estudantes sejam contempladas desde o planejamento de uma ação docente.

Para Santos (2018), existe uma relação direta entre a motivação dos alunos para os estudos e a relevância dada aos assuntos ensinados pelos professores em sala de aula. Quanto mais os conteúdos corresponderem às suas reais expectativas, mais importância será dada aos assuntos e, consequentemente, desencadeará um fator de predisposição motivacional favorável à aprendizagem.

Esses fatores, motivação dos alunos e relevância dos assuntos, vai despertar um comportamento indutor no desejo de aprender dos alunos que gera um fator emocional que a concepção humanista da aprendizagem defende em sua fundamentação.

A abordagem humanista da educação está centrada nos pilares:

- Valorização do ser humano como pessoa;

- Interação social entre os sujeitos;

- Crescimento pessoal;

- Papel do professor como facilitador da aprendizagem;

- Estudante como protagonista em busca de autonomia para aprender a aprender.

\section{Concepção humanista na visão de Carl Rogers}

A concepção humanista na visão de Carl Rogers - classificada em muitos estudos como abordagem rogeriana - considera o ser humano em sua completude. Embora não abra do intelecto, Rogers considera sentimos e emoções extremamente importantes para uma aprendizagem duradoura e profunda dos estudantes em seu processo formativo. Moreira (1999) enfatiza que a abordagem rogeriana para a aprendizagem é governada pelo que Rogers chamou de "princípios de aprendizagem", e não por uma "teoria de aprendizagem" propriamente dita.

As contribuições de Rogers partiram da sua experiência como psicólogo, na qual ele entendia que as pessoas podiam buscar respostas para os seus problemas dentro de si mesmas (psicologia humanística) e pela forma como percebem e compreendem o mundo ao seu redor (psicologia fenomenológica). No contexto educacional, as potencialidades do aluno para o aprendizado podem ser identificadas quando a sua capacidade de autoconhecimento e a sua percepção do ambiente são, de maneira indissociável, levadas em consideração pelo professor.

Rogers defende uma aprendizagem que chamou de significante. É uma aprendizagem que perpassa a pura e simples acumulação de fatos com fins de memorização e o significado cognitivo (definido por Ausubel como aprendizagem significativa). A aprendizagem significante, também chamado por Rogers de duradoura ou penetrante, modifica a percepção, a compreensão e a atitude da pessoa, estando, intimamente, ligada às emoções e sentimentos do aluno enquanto ser em sua totalidade. Essa totalidade envolve, em sua completude, sentimentos (afetividade) e intelecto, de modo que o aluno passa a ser apropriar daquilo que está aprendendo.

A abordagem rogeriana é muito crítica ao ensino tradicional e considera que as formulações 
ANDRADE, D. E. da S.; NETO, A. F. P. P.; OLIVEIRA, C. A. de; BRITO, J. A.(2019). Comportamentalismo, Cognitivismo e Humanismo: uma revisão de literatura

levantadas para o ensino propõem questões inadequadas para que uma aprendizagem significante, de fato, se concretize. Moreira (1999) enfatiza a perspectiva de Roger ao destacar:

Para Rogers, o objetivo desse sistema, desde os primeiros anos até a pósgraduação, deve ser a facilitação da mudança e da aprendizagem. A sociedade atual se caracteriza pela dinamicidade, pela mudança, não pela tradição, pela rigidez. 0 homem moderno vive em um ambiente que está continuamente mudando. 0 que é ensinado torna-se rapidamente obsoleto. Nesse contexto, o único homem educado é o que aprende a aprender; o homem que aprendeu a adaptar-se e muda; que percebeu que nenhum conhecimento é seguro e que só o processo de busca do conhecimento dá uma base para a segurança (MOREIRA, 1999, p. 145).

Rogers defendia o papel do professor como um facilitador da aprendizagem, o qual deve estabelecer uma relação diferente do que usualmente professores e alunos têm no ensino tradicional. Saindo de uma posição centralizadora adotada no ensino tradicional, o professor, como facilitador, deve ser autêntico, sincero e verdadeiro para conquistar a confiança na relação estabelecida com os seus alunos. A compreensão e a confiança (aceitação) também são requisitos importantes - e necessários - que o professor-facilitador deve apresentar para desenvolver uma relação interpessoal que permita a conexão afetiva com o aprendiz (estudante) na direção de uma experiência vivencial que contribua para uma aprendizagem significante.

$\mathrm{Na}$ figura de professor-facilitador, dentro da abordagem rogeriana de ensino, o aluno passa a ocupar uma posição de protagonista, a qual Moreira (1999) conclui que ela:

Implica que o ensino seja centrado no aluno, que a atmosfera da sala de aula tenha o estudante como centro. Implica confiar na potencialidade do aluno para aprender, em criar condições favoráveis para o crescimento e auto realização do aluno, em deixá-lo livre para aprender, manifestar seus sentimentos, escolher suas direções, formular seus próprios problemas, decidir sobre seu próprio curso de ação, viver as consequências de suas escolhas. (MOREIRA, 1999, p. 147).

Portanto, para Rogers, o ensino deve ser centrado no aluno, ou seja, que se distancie do modelo tradicional de ensino, o qual é centrado na autoridade impositiva do professor e no ensino conteudista. Fugindo deste modelo tradicional e colocando o estudante no centro do processo de aprendizagem, o professor passaria a exercer - efetivamente - o papel de facilitador, contribuindo para que a aprendizagem significante possa ser desenvolvida em sua plenitude.

A Escola Nova, movimento de renovação do ensino brasileiro que aflorou em 1932 com a publicação do Manifesto dos Pioneiros da Educação Nova, sofreu influência das ideias rogerianas. 0 estudante no centro do processo educativo e a valorização da experiência de vida, entre outros itens, foram aspectos que permearam os ideais do Movimento Escolanovista (SANTOS, 2018).

\section{Concepção humanista na visão de Paulo Freire}

Paulo Freire sempre militou em prol de uma educação que fosse além da simples instrução e memorização. Considerado um dos educadores brasileiros mais respeitados no mundo, sua extensa e relevante obra sempre foi permeada por uma ideologia política voltava para a pedagogia numa perspectiva libertadora que mobilize o indivíduo para a transformação social. Esta visão freireana 
ANDRADE, D. E. da S.; NETO, A. F. P. P.; OLIVEIRA, C. A. de; BRITO, J. A.(2019) Comportamentalismo, Cognitivismo e Humanismo: uma revisão de literatura

de educação, mais do que um método, em seu conceito estrito, segundo Gadotti (1999) é, na verdade, uma teoria do conhecimento e uma filosofia educacional, embora o trabalho de Freire voltado para a alfabetização de adultos, sobretudo o seu projeto realizado em 1962 em Angicos (RN), tenha ganhado notoriedade e recebido o nome de "método freireano de educação".

Para Osterman e Cavalcanti (2011), Freire sempre defendeu "que existe uma sabedoria popular, ou seja, os alunos trazem consigo vivências, conhecimentos e hábitos que devem ser levados em conta no sentido de uma conscientização visando, como fim, a uma transformação social". Portanto, mediante orientação de um educador, a pedagogia freireana (libertadora) defendia com ênfase que o levantamento de discussões e o compartilhamento das experiências de vida e anseios das pessoas poderiam contribuir ricamente com o processo educativo.

$\mathrm{Na}$ perspectiva freireana, tanto a educação tradicional, marcada por uma aprendizagem de cunho autoritário e mecânico, quanto a educação "renovada", tinham caráter meramente domesticador, tendo em vista que não favoreciam efetivamente para despertar no indivíduo um nível de consciência de si e do seu contexto (meio) para questionar a realidade estabelecida. Ele defendia que a consciência da realidade é que gera os questionamentos necessários à mobilização política para a transformação social - cerne de pedagogia libertadora freireana.

Segundo Freire e Shor (1986), o currículo educacional tradicional de transferência de informações - marcado, fortemente, pelo autoritarismo - pouco contribui para que o professor explore suas capacidades plenas, nem tampouco permite ao estudante desenvolver todo o seu potencial criativo. Como um ferrenho opositor desse modelo tradicional de educação, Freire utilizava o termo educação bancária para se referir aos métodos adotados por este modelo, no qual o professor - que tudo sabia - "depositava” o conhecimento na mente dos alunos - que nada sabiam.

Freire sempre foi afirmativo ao defender uma hierarquia horizontal entre educador e educando, na qual aluno e professor aprendem juntos por meio de uma intensa interação e participação igualitária no processo educativo. A afetividade construída por meio dessa interação entre professor aluno é uma característica marcante que também está presente na pedagogia rogeriana, a qual defende em seus fundamentos que os sentimentos e as emoções são variáveis determinantes na na construção de uma aprendizagem duradoura e profunda, que Rogers chamou de aprendizagem significante.

Do ponto de vista da transposição da pedagogia freireana para a educação formal, tendo em vista que, segundo Osterman e Cavalcanti (2011), essa pedagogia foi experimentada numa situação não formal, existe um percurso nada trivial a ser seguido em termos de pesquisas em maior profundidade para uma sistematização do método, embora muitos educadores engajados numa educação escolar transformadora já tenham experimentado muitos pressupostos freireanos e colhidos bons frutos.

\section{Conclusões}

A Educação Profissional e Tecnológica (EPT) é um campo da educação que, antes de formar para o mundo do trabalho, deve ter como premissa formar um cidadão - futuro profissional - para a 
ANDRADE, D. E. da S.; NETO, A. F. P. P.; OLIVEIRA, C. A. de; BRITO, J. A. (2019) Comportamentalismo, Cognitivismo e Humanismo: uma revisão de literatura

vida. Educar para um mundo de incerteza em constante transformação tem sido o desafio do professor desse novo século. As origens da educação profissional têm em suas bases um ranço de uma educação de "segunda categoria", criada para as massas proletárias e desvalidos da sorte. Com o processo de industrialização, a educação profissional passa a ter como missão qualificar para o mercado de trabalho, contudo ainda dentro de uma perspectiva meramente instrumental e domesticadora, atendendo, prioritariamente aos interesses da classe industrial. Romper essas barreiras históricas limitantes da educação profissional deve ser o compromisso de todo educador. Portanto, é pensando na direção de uma educação libertadora que as teorias de aprendizagem devem ser entendidas.

Seja no campo comportamentalista, cognitivista ou humanista, as teorias de aprendizagem devem ser entendidas de forma crítica pelo professor. Buscar elementos nessas teorias, sejam conceituais ou metodológicos, que possam contribuir para uma Educação Profissional e Tecnológica (EPT) transformadora, numa perspectiva de formação omnilateral e libertadora, deve ser um compromisso buscados por nós que buscamos uma educação de qualidade em nosso país.

Como essa pesquisa foi baseada em uma revisão de literatura do tipo narrativo, apenas oferecendo uma introdução aos temas propostos, para um maior entendimento dos temas abordados será necessário a consulta de uma bibliográfica mais robusta que explane com mais riqueza de detalhes os temas abordados em nosso artigo.

Embora a revisão narrativa deste artigo tenha recorrido a um referencial teórico substancial sobre as teorias de aprendizagem (comportamentalismo, cognitivismo e humanismo), essa busca não esgotou o vasto campo de fontes de informação sobre o tema. Futuramente, recorrendo a uma estratégia metodológica mais criteriosa e sofisticada para a revisão bibliográfica da literatura, seja por meio de uma revisão sistemática ou integrativa, essa pesquisa poderá fornecer elementos mais consistentes que possam revelar contribuições significativas desses campos teóricos para a Educação Profissional e Tecnológica (EPT).

\section{Referências}

ANACLETO, Verônica Gomes et al. Teorias da aprendizagem: os principais conceitos e a relação com o contexto escolar. In: CONGRESSO NACIONAL DE EDUCACÃO, 2. 2015, Campina Grande, Anais... Campina Grande: CONEDU, 2015. Disponível em: http://www.editorarealize.com.br/revistas/conedu/trabalhos/TRABALHO_EV045_MD1_SA3_ID7441_ 30082015201703.pdf. Acesso em: 23 de abril 2019.

BERNARDO, Wanderley Marques; NOBRE, Moacyr Roberto Cuce; JATENE, Fábio Biscegli. A prática clínica baseada em evidências. Parte II: buscando as evidências em fontes de informação. Revista da Associação Médica Brasileira, São Paulo, v. 50, n. 1, p. 1-9, 2004.

BOCK, Ana Mêrces Bahia; FURTADO, Odair; TEIXEIRA, Maria de Lourdes Trassi. Psicologias: uma introdução ao estudo de psicologia. 13. ed. São Paulo: Saraiva, 2001. 492 p.

CEZAR, Adieliton Tavares. Gestaltpedagogia: um caminho trilhado na intersubjetividade. Debates em Educação, Maceió, v. 10, n. 20, p. 143-154, jan./abr. 2018. Disponível em: http://www.seer.ufal.br/index.php/debateseducacao/article/download/3626/pdf. Acesso em: 30 de mar. de 2019. 
ANDRADE, D. E. da S.; NETO, A. F. P. P.; OLIVEIRA, C. A. de; BRITO, J. A.(2019). Comportamentalismo, Cognitivismo e Humanismo: uma revisão de literatura

DELLA MONICA, Glória. Instrução programada. Rev. adm. empres. v.17 n. 3, São Paulo Maio/Jun. 1977. Disponível em: http://www.scielo.br/scielo.php?script=sci_arttext\&pid=S003475901977000300012. Acesso em: 15 de abril 2019.

FILIPPI, Adriana; BORTOLINI, Camila Comin; DIAS, Rosângela Hanel. Metacognição: o elo de significação entre método, avaliação e aprendizagem. In: SEMINÁRIO DE PESQUISA DA REGIÃO SUL, 9. 2012, Caxias do Sul, Anais... Caxias do Sul: ANPED SUL, 2012. Disponível em: http://www.ucs.br/etc/conferencias/index.php/anpedsul/9anpedsul/paper/viewFile/2186/92. Acesso em: 22 de abril 2019.

FREIRE, I. R. Raízes da Psicologia. 7. ed. Petrópolis: Vozes, 2002. Disponível em: https://pt.slideshare.net/AlinedeAndrade/raizes-da-psicologia?from_action=save. Acesso em: 15 de abril 2019.

FREIRE, Paulo. Pedagogia da autonomia: os saberes necessários à prática educativa. 25. ed. São Paulo: Paz e Terra, 1996.

FREIRE, Paulo; SHOR, Ira. Medo e ousadia: o cotidiano do professor. Rio de Janeiro: Paz e Terra, 1986.

GADOTTI, Moacyr. Paulo Freire: su vida y su obra. Bogotá: Codecal, 1991.

GARDNER, Howard. La nueva ciencia de la mente: historia de la revolución cognitiva. Buenos Aires: Paidós, 1987. Disponível em: https://pt.scribd.com/doc/89526951/Gardner-Howard-1985-LaNueva-Ciencia-de-La-Mente. Acesso em: 19 de abril 2019.

GOMES FILHO, joão. Gestalt do objeto: sistema de leitura visual da forma. 8. ed. São Paulo: Escrituras, 2008. $122 \mathrm{p}$.

KAULFUSS, Marco Aurélio. Behaviorismo: conceitos e preconceitos. Rev. Eletrônica de Ciências Aplicadas da FAIT, [s.l.], 6. ed., p. 1-12, nov. 2015. Disponível em: http://fait.revista.inf.br/imagens_arquivos/arquivos_destaque/QTQkycuoQSWB6PR_2017-1-21-1043-24.pdf. Acesso em: 15 de abr. 2019.

LA ROSA, Jorge. Psicologia e educação: o significado do aprender. 7. ed. Porto Alegre: EDIPUCRS, 2003. Disponível em: https://books.google.com.br/books?hl=pt-BR\&lr=\&tid=K2Lf-uSQtOC\&oi=fnd\&pg=PA39\&dq=pavlov+e+o+condicionamento\&tots=dZIwnN9tYz\&sig=PSzXgEifHzuwIC6eUwj wDbdtGAk\#v=onepage\&q=pavlov\%20e\%20o\%20condicionamento\&f=false. Acesso em: 16 de abril de 2019.

LEFRANÇOIS, Guy R. Teorias da aprendizagem: o que o professor disse. 2. ed. São Paulo: Cengage, 2017. $475 \mathrm{p}$.

LEÃO, Marcelo Franco. F. Ensinar química por meio de alimentos: possibilidades de promover alfabetização científica na educação de jovens e adultos. 2014. 190 f. Dissertação (Mestrado em Ensino) - Programa de Pós-Graduação em Ensino, Centro Universitário UNIVATES, Lajeado, 2014. Disponível em: https://www.univates.br/bdu/bitstream/10737/811/1/2014MarceloFrancoLeao.pdf. Acesso: 25 de abril 2019.

LEÃO, Marcelo Franco; DUTRA, Mara Maria. Influências do comportamentalismo, cognitivismo e humanismo na prática pedagógica de alguns professores de ciências da região do Baixo Araguaia (MT). Revista Educação em Debate, Fortaleza, v. 40, n. 76, p. 146-162, mai./ago. 2018.

MAIA, Adriana Moura; CUNHA, Francisco Roberto Brito. Psicologia da educação: essência da educação emancipatória. Id on Line Rev. Psi., Jaboatão dos Guararapes, v. 11, n. 34, p. 104-110, fev. 2017. Disponível em: https://idonline.emnuvens.com.br/id/about/contact. Acesso em: $31 \mathrm{de}$ mar. 2019.

MARCONI, Marina de Andrade; LAKATOS, Eva Maria. Metodologia do trabalho científico. 8. ed. São Paulo: Atlas, 2018. 
ANDRADE, D. E. da S.; NETO, A. F. P. P.; OLIVEIRA, C. A. de; BRITO, J. A.(2019). Comportamentalismo, Cognitivismo e Humanismo: uma revisão de literatura

MARQUES, Tania Beatriz Iwaszko; SLOMP, Paulo Francisco. Gestalt: material didático. Disponível em: https://www.ufrgs.br/psicoeduc/a-gestalt/c32.htm. Acesso em: 31 de mar. 2019.

MOREIRA, Marco Antonio. Teorias de aprendizagem. 2. ed. ampl. São Paulo: E.P.U., 2019.

MOREIRA, Marco Antonio. Aprendizagem significativa em mapas mentais. Textos de Apoio ao Professor de Física, Bento Gonçalves, v. 24, n. 6, p. 1-49, 2013. Disponível em: http://www.if.ufrgs.br/ppgenfis/textos_apoio. Acesso em: 20 de abril 2019.

MOREIRA, Marco Antonio. Comportamentalismo, construtivismo e humanismo: Coletânea de breves monografias sobre teorias de aprendizagem como subsídio para o professor pesquisador, particularmente da área de ciências. 2. ed. Porto Alegre: UFRGS, 2016. Disponível em: <https://www.if.ufrgs.br/ moreira/Subsidios5.pdf>. Acesso em: 22 abr. 2019.

MOREIRA, Marcos Antonio. Coletânea de breves monografias sobre teorias de aprendizagem como subsídio para o professor pesquisador, particularmente da área de ciências. 2. ed. rev. Porto Alegre: [s.n], 2016. 64 p. Disponível em: https://www.if.ufrgs.br/ moreira/Subsidios5.pdf. Acesso em: 15 de abril 2019.

MOREIRA, Marcos Antonio. Teorias de aprendizagem. São Paulo: EPU, 1999. 195 p.

NEVES, Rita de Araújo; DAMIANI, Magda Floriana. Vygotsky e as teorias de aprendizagem. UNIrevista, São Leopoldo. Unisinos, v. 1, n. 2, p. 1-10, 2006.

NIEMANN, Flávia de Andrade; BRANDOLI, Fernanda. Jean Piaget: um aporte teórico para o construtivismo e suas contribuições para o processo de ensino e aprendizagem da Língua Portuguesa e da Matemática. In: SEMINÁRIO DE PESQUISA DA REGIÃO SUL, 9. 2012, Caxias do Sul, Anais... Caxias do Sul: ANPED SUL, $2012 . \quad$ Disponível http://www.ucs.br/etc/conferencias/index.php/anpedsul/9anpedsul/paper/viewFile/770/71. Acesso em: 22 de abril 2019.

OSTERMANN, Fernando; CAVALCANTI, Cláudio José de Holanda. Teorias de aprendizagem. Porto Alegre: UFRGS, 2011. 58 p.

PERLS, Fritz. A abordagem gestáltica e testemunha ocular da terra. 2. ed. Rio de Janeiro: LTC, c1988.

PRODANOV, Cleber Cristiano; FREITAS, Ernani Cesar de. Metodologia do trabalho científico: métodos e técnicas da pesquisa e do trabalho acadêmico. Novo Hamburgo, RS: 2013. 277 p.

PRÄSS, Alberto Ricardo. Teorias de aprendizagem. [s.l.]: ScriniaLibris, 2012. 57 p.

PÁDUA, Elisabete Matallo Marchesini de. Metodologia da pesquisa: abordagem teórico-prática. Campinas, SP: Papirus, 2018. 1 Epub. (Coleção Magistério: Formação e Trabalho Pedagógico).

RABATINI, Vanessa Gertrudes. A concepção de cultura em Bruner e Vigotski: implicações para a educação escolar. 2010. 126 f. Dissertação (Mestrado em Educação Escolar) - Faculdade de Ciências e Letras, Universidade Estadual Paulista, Araraquara, 2010. Disponível em: https://repositorio.unesp.br/bitstream/handle/11449/92407/rabatini_vg_me_arafcl.pdf?sequence= 1 \&isAllowed=y. Acesso em: 20 de abril 20019.

RANGEL, Annamaria Píffero. Psicologia da educação. [s.l.:s.n]: [2001]. Disponível em: http: / / webcache.googleusercontent.com/search?q=cache:uKpymwL6uFsJ:https://docplayer.com.br /4369026-Psicologia-da-educacao-annamaria-piffero-rangel.html\&client=ubuntu\&hl=pt-

BR\&gl=br\&strip=1\&vwsrc=0. Acesso em: 29 de mar. 2019.

RESENDE, Cibele Caetano. Contribuições teóricas educacionais B. Skinner: a teoria condutista e suas aplicabilidades na educação. In: MOREIRA, Tiago Bacciotti (Org.). A cultura virtual e as práticas docentes. Uberlândia, MG: Navegando, 2018. Disponível em: https://www.editoranavegando.com/livro-a-cultura-virtual-e-as-praticas-docentes. Acesso em: 16 
ANDRADE, D. E. da S.; NETO, A. F. P. P.; OLIVEIRA, C. A. de; BRITO, J. A.(2019) Comportamentalismo, Cognitivismo e Humanismo: uma revisão de literatura

de abril 2019.

SANTOS, José Alex Soares. Teorias da aprendizagem: comportamentalista, cognitivista e humanista. Revista Sigma, n. 2, p. 97-111, 2008. Disponível em: <http://aprendizagemhumanista.weebly.com/uploads/6/9/4/2/6942932/teorias_da_aprendizagem_ comportamentalista_cognitivista_e_humanista.pdf>. Acesso em: 20 abr. 2018.

SILVA, Alisson Henrique; GOMES, Luciano Carvalhais. A teoria de aprendizagem de Bruner e ensino de ciências. Arquivos do Museu Dinâmico Interdisciplinar, Maringá, v. , n. 3, p. 13-25, 2017. Disponível em: http://ojs.uem.br/ojs/index.php/ArqMudi/article/viewFile/40938/pdf. Acesso em: 20 de abril 2019.

STERNBERG, Robert J. Psicologia cognitiva. 4. ed. Porto Alegre: Artmed, 2008. 584 p.

VARELA-RUIZ, Margarita. Apontaciones del cognoscitivismo a la enseñanza de la medicina. Gaceta médica México, v. 140, n. 3, p. 307-308, mayo/junio 2004. Disponível em: http://www.scielo.org.mx/pdf/gmm/v140n3/v140n3a8.pdf. Acesso em: 19 de abril 2019.

VYGOTKSY, L. S. A formação social da mente. 4. ed. São Paulo: Martins Fontes, 1991. 